\title{
O ALGARVE VISTO DO CÉU UM DOCUMENTO GEOGRÁFICO IMPORTANTE E DE GRANDE BELEZA
}

Carminda CaVACO ${ }^{1}$

O Algarve visto do céu, um excelente livro de fotografias, do arquitecto Filipe Jorge, encanta, estou certa, muitos dos seus leitores, geógrafos e não geógrafos. São muitas as fotografias, a diferentes escalas, e ricos os seus pormenores. Acompanhamnas textos de enquadramento, em português e em inglês, de um conjunto de autores, especialistas e profundos conhecedores da região, de Fernando Pessoa, João Bernardes, José Horta Correia, Miguel Reimão Costa a João Guerreiro, que dispensam qualquer apresentação. A edição é da ARGUMENTUM (2005) e contou com o patrocínio da Associação de Municípios do Algarve e da Faro Capital Nacional da Cultura 2005.

A apresentação deste belo livro é para mim uma ocasião de revisitar o Algarve, a diferentes escalas e sob diversas perspectivas, muitos anos depois, dezenas de anos depois, do início da aceleração dos processos de mudança, a qual acompanhei, e até mesmo vivi de perto, e que lhe permitiram ultrapassar as crises das suas economias tradicionais, de base agrícola, piscatória e conserveira, contrariar a fuga da sua gente, das suas elites e dos menos dotados, para outras regiões do país e para muitos destinos clássicos de emigração, tornando-se numa das regiões portuguesas mais desenvolvidas, no sentido global do termo, e de maior projecção europeia e mundial. Revisitação aliás facilitada pela inclusão no livro de algumas fotografias antigas, de quase meio século, que ajudam a recordar o passado e evidenciam as próprias intensidades da mudança e do desenvolvimento.

O Algarve visto do céu é, na verdade, e antes de mais, um vasto conjunto de imagens muito belas e muito actuais, que cobrem todo o território algarvio, do litoral ocidental e meridional às superfícies que dos seus cimos algo montanhosos descem para Norte, com alguma suavidade, ao encontro das planuras do Baixo Alentejo, e evidenciam a sua unidade e a sua diversidade. Imagens das massas de água oceânicas de um azul-turquesa ou esverdeado, em harmonia com o azul dos céus, ora revoltas ora calmas, no encontro das arribas vigorosas da costa ocidental ou das arribas rendilhadas da costa do Barlavento, dos cordões dunares, com suas barras instáveis, das embocaduras dos rios e ribeiras, dos sapais, mouchões, esteiros e salinas, sobretudo no Sotavento. Salinas ainda tradicionais ou já modernas e de malhas bem

1 Investigadora do Centro de Estudos Geográficos e Professora Catedrática da Faculdade de Letras da Universidade de Lisboa. 
mais largas, expressas em geometrismos reluzentes e prateados, em contraste com as superfícies líquidas e espelhadas das barragens onde os contornos são sinuosos, ao sabor dos caprichos da topografia dos xistos onde foram construídas. Imagens a que se juntam, pela vizinhança, as das pequenas "cidades de plástico", também ele luzidio, da campina de Faro-Olhão, pela modernização das técnicas tradicionais de forçagem para produção de primores hortícolas, no que o Algarve litoral cedo se especializara, contando primeiro com a cabotagem e depois com o comboio da noite, que levava para a capital do Reino e da República o correio, alguns passageiros e os produtos da horta e dos pomares, e na Primavera também as favas e ervilhas dos campos de sequeiro do Barrocal.

Um percurso "pelas imagens do céu" que nos são proporcionadas permite-nos, com efeito, viajar das paisagens fortemente humanizadas do litoral aos desertos humanos das terras serranas ou das vertentes do Mira e do Guadiana; observar pormenores das estruturas antigas do povoamento e das cidades, como em muitas fotografias de Alcoutim e do Carvoeiro, com o seu velho casario acompanhando as curvas de nível, ou noutras fotografias que evidenciam os cascos antigos de cidades como Silves, Tavira ou Faro, com suas muralhas e castelos; fotografias que Filipe Jorge combinou hábil e criteriosamente com algumas outras de arquivo, de modo a evidenciar os sentidos e os próprios ritmos das expansões do casario. Permite-nos identificar, por exemplo, a antiga organização do espaço urbano de Tavira por uma e outra margem do Gilão e a sua ligação por uma velha ponte romana, e a que não escapou, no bater da chapa, a permanência de um velho arraial de armação de atum, símbolo do mais recente ciclo de desenvolvimento económico da cidade antes do turismo, embora adaptado a complexo hoteleiro moderno. Permite-nos reconhecer a génese Vila Real de Santo António, com o seu geometrismo planeado à imagem da reconstrução da Baixa de Lisboa, também ela pombalina, e a dignidade da sua fachada fluvial, justamente frente a Espanha, como convinha para a defesa dos direitos nacionais de comércio e sobre as pescarias nas costas da província, em particular nas do Sotavento, nomeadamente em Monte Gordo. Sem esquecer as estruturas e equipamentos modernos, dos muitos aldeamentos turísticos aos portos de recreio, às marinas e campos de golfe e ao novíssimo estádio do Algarve, passando pelas várias fases da construção e funcionamento do aeroporto de Faro, pelos grandes complexos logísticos dos sistemas de distribuição e pelos grandes centros comerciais.

São fotografias que jogam não apenas com diferentes escalas mas igualmente com diferentes perspectivas, acompanhadas por textos também eles traduzindo diferentes sensibilidades, que agradarão tanto os naturalistas e os que preferem fugir aos humanos, ou os nostálgicos de um velho Algarve dos algarvios - obviamente de uma dada geração de algarvios, que integrara as mestiçagens anteriores, dos nórdicos aos africanos e orientais - e não menos agradarão os que amam a presença e a proximidade dos seus semelhantes e valorizam a compreensão das suas obras e a criação dos seus territórios ao longo dos tempos e no presente, com projecção no futuro.

Impressiona, desde logo, a fotografia de abertura, uma imagem Land Sat de todo o Algarve, numa escala adequada para se apreciar correctamente a ocupação da totalidade do território: nesta sobressai, de imediato, um espaço que permanece vazio na sua grande extensão, nomeadamente na costa vicentina e nas serras de Monchique e Caldeirão, espaços montuosos deixados aos processos naturais, ainda predominantemente rudes e com algumas manchas com tonalidades sugestivas de aridez, ou das queimadas dos grandes incêndios dos últimos anos, onde são muito escassas, difusas e mesmo ténues 
as marcas de ocupação humana. Espaços que são domínio de matos densos, como antes da Campanha do Trigo, com predomínio cada vez mais acentuado de estevas e aqui e além de montado, quando mais húmidos, que foram terra de pastoreio de rebanhos de caprinos e ovinos e de varas de porcos e também de transumância de colmeias, de carvoeiros vivendo do fabrico e da exportação de carvão de sobro e azinho para as cidades andaluzas, acessíveis pelo Guadiana, por mar e pelo Guadalquivir, que o pagavam bem melhor que as do Algarve, sem esquecer o corte de árvores para a construção de barcos, que também fora preciso disciplinar e mesmo proibir. Matos que, sob a pressão da sobrevivência alimentar de populações rurais que se tornavam mais numerosas, nomeadamente durante o século XIX e na primeira metade do século XX, foram dando lugar a cultivos primitivos, em que às arroteias se seguiam queimadas e às parcas colheitas longos pousios, e que mais tarde, quando os meios de sobrevivência se tornavam ainda mais escassos, foram seguidos de colonização e povoamento, num processo topograficamente ascendente, pelas populações periféricas, o que a toponímia atesta com o desdobramento dos nomes das aldeias e sobretudo de simples lugares como, por exemplo, Marrocos de Baixo, de Cima e do Meio.

No fundo, um sertão que fora marginalizado pela economia tradicional, e continua sendo-o pelas economias modernas, em relação ao qual não vão bastando as políticas florestais, as ajudas ao desenvolvimento rural e muito menos as utopias de interiorização do turismo e de promoção de turismo rural e de ecoturismo, já que no turismo, como noutros sectores, quem comanda são as procuras, e com elas as sustentabilidades económicas, e não as boas vontades ideológicas e as acumulações de subsídios.

Mas nesta fotografia inicial do conjunto do território sobressai, de igual modo, a concentração das manchas do povoamento na planície litoral e sobretudo na frente marítima, um pouco também nas encostas mais suaves das superfícies miocénicas e na depressão periférica do Maciço Antigo, ao longo da qual fora mais fácil assegurar as deslocações este-oeste, desde o tempo dos Árabes, como o testemunha o alinhamento de algumas cidades históricas, com destaque para Silves, Loulé e Tavira, embora se não deva esquecer que todas estas gozaram de acessibilidade marítima, pelo Arade, pelo Ludo ou pelo Gilão. Testemunham que o Algarve sempre foi, ao longo da sua história, uma terra virada ao mar, com uma ocupação essencialmente costeira, mesmo quando esse mar não simbolizava apenas outros mundos e outras gentes e a possibilidade de trocas, de chegada de recursos complementares para uma economia que cedo deixara de ser autárcica e de novas e renovadas oportunidades de futuro, mas também invasões e ataques de corsários.

A estas escalas de conjunto e portanto, a estas distâncias do céu, também se podem ler com alguma facilidade os grandes contrastes na ocupação dos espaços rurais do Algarve litoral e do Barrocal, das terras planas e das encostas pedregosas, e até mesmo as cicatrizes das pedreiras de brita e do cimento, e identificar os matos também vazios de homens da Rocha dos Soidos, da Rocha da Pena, do Cabeço da Câmara, do Malhão ou de São Miguel. Destaco, para já, os arranjos dos campos do Barrocal, muitos algo recentes, com menos de um século, e algo conjunturais, fruto do esforço insano do homem nas despedregas feitas a picareta, aquando dos máximos demográficos dos anos 30 a 50 do século passado, sempre sob a pressão das necessidades de sobrevivência das populações camponesas, mesmo se também norteadas pelas oportunidades do mercado, e que se adivinham ainda hoje nas espessuras dos velhos valados que os limitam ou mesmo ponteiam, cujas funções de vazadouro se sobrepunham às de limite e protecção da propriedade privada. 
No fundo, são também neste caso o resultado das estratégias de sobrevivência das populações que não ousaram o êxodo proporcionado pelo caminho-de-ferro, os modestos empregos disponibilizados na polícia, na guarda fiscal ou no exército, ou nas oficinas dos caminhos-de-ferro e da CUF, do Barreiro, nem acompanharam a deslocalização, para empregar um termo muito em voga, das fábricas de cortiça de Silves e de São Brás de Alportel para a margem sul do Tejo, onde era bem maior a acessibilidade a novos mercados, internos e sobretudo externos. Populações para quem se tinham fechado os tradicionais caminhos da emigração para o Brasil, a Argentina ou a Venezuela e não se reabriam as portas de entrada nos EUA, Canadá e sobretudo na Espanha e na França, como veio a suceder nesta última nos finais dos anos 50, com intensidades que aliás desequilibraram totalmente as relações entre forças de trabalho e sistemas de cultivo e produção, e no seu seguimento, o avanço dos incultos e depois dos matos, o abandono de quase todos os cultivos e mesmo das parcas colheitas arbóreas, numa simples estratégia de recolecção moderna, apesar do desenvolvimento de novos fluxos humanos, primeiro sazonais e depois definitivos, o dos rurais sem terra do Baixo Alentejo, mesclando e enriquecendo um pouco mais culturas e tradições locais.

Nestas texturas complexas da ocupação e valorização das terras do Baixo Algarve destacam-se algumas clareiras, facilmente identificáveis em muitas das imagens que nos são proporcionadas, pela regularidade e homogeneidade das plantações de pomares de sequeiro e regadio. Tais clareiras aparecem associadas a grandes propriedades, de antigas famílias fundiárias nobilitadas pelas conquistas e descobertas, do Norte de África à Índia e ao Brasil. Terras de morgados, que mantêm o nome, muito tempo depois da sua apropriação pela nova burguesia regional, nacional e sobretudo estrangeira, nomeadamente espanhola, mas também italiana e inglesa, uma burguesia do comércio dos frutos secos e da cortiça, e sobretudo das épocas áureas da pesca e das conservas de peixe. Algumas outras grandes propriedades, morgados, quintas e mesmo herdades quando estendidas pelas encostas das serras de xisto, foram dando lugar a resorts e aldeamentos turísticos mais ou menos sofisticados, com lugar para zonas de caça e sobretudo campos de golfe, não menos exigentes em trabalho e por certo bem mais lucrativos. Destaco as muitas fotografias da Quinta do Lago, de Vale do Lobo e sobretudo de Vilamoura, cuja história fundiária e agrícola me é mais familiar.

Mas este belo livro, que convida à contemplação das suas imagens, é ao mesmo tempo um documento importante para o conhecimento, e não menos a promoção e divulgação do Algarve, a nível nacional e a nível internacional. Uma síntese das permanências e mudanças, das harmonias e das roturas e descontinuidades na ocupação do espaço, das suas malhas, estruturas e até funcionalidades, dos percursos do seu ordenamento, claramente simbolizados pelas magníficas fotografias das elegantes pontes de Portimão e Castro Marim, a beleza dos novos trevos das suas mui jovens autoestradas, as superfícies prateadas pelos raios do sol incidentes nos lagos interiores das não menos jovens barragens. Estas foram sendo construídas para responder a procuras crescentes de água por parte de populações também elas crescentes, de visitantes e não menos de residentes, que o Algarve tem contrastado fortemente com as demografias recessivas das outras regiões do país, e não apenas através da atracção e fixação de populações idosas e reformadas fugindo aos rigores dos Invernos nórdicos; e também para ultrapassar as velhas e repetidas carências estivais no abastecimento do precioso líquido das populações rurais, quando era preciso madrugar e ainda com o luar aparelhar as bestas com os cântaros de barro e procurá-lo em algum poço mais profundo ou melhor 
alimentado pela circulação subterrânea nos calcários, por vezes a quilómetros de distância da casa de residência.

O Algarve visto do céu é também um documento das identidades locais, como o comprovam as imagens espectaculares das açoteias de Olhão, as novas e as mais antigas, que são bem mais complexas, com os seus pisos embutidos, até ao mirante, e que evocam o Norte de África e as ligações intensas das suas comunidades piscatórias e marítimas com as populações do outro Al-Gharb. Açoteias de difusão comum à Fuzeta, aglomerado piscatório que acompanhou a dinâmica de Olhão como seu subúrbio residencial, e que com ele, com Cabanas, Monte Gordo ou Quarteira e a Luz de Lagos, partira das primitivas cabanas de colmo, substituídas por casas de pedra e cal só a partir dos séculos XVIII ou XIX e ainda facilmente observáveis nos meados do século $\mathrm{XX}$. Ou como o comprovam os castanheiros da serra de Monchique, neste caso especificidade botânica associada à natureza dos terrenos sieníticos e à frescura do clima, pela altitude e exposição aos ventos dominantes atlânticos e de Noroeste, sem esquecer a abundância de chuvas, ocasionalmente a presença de neve, em contraste com as terras baixas envolventes, como que "o penico do céu", na observação do povo; castanheiros que vêm assegurando madeiras para o artesanato local, mas que também produziam castanhas, facto único na província, evocado em versejos populares, como "as donzelas de Monchique são bonitas mas sem dentes, porque bebem água fria e comem castanhas quentes". Sem esquecer o contraste das moles sieníticas elevando-se a cerca de 900 metros com o soco de xisto em torno dos 400 metros, com os seus medronheiros e sobreiros, em cujo contacto se localizam as termas, velho recurso terapêutico, que fora muito procurado pelas populações de Lisboa e de todo o Sul, mesmo da Andaluzia, não obstante a difícil acessibilidade e a necessidade de mobilização do transporte por barco, pelo Guadiana para as do interior alentejano e as espanholas, pelo mar para as do litoral meridional e ocidental, e pelo Arade para umas e outras.

Especificidades também das terras drenadas e pantanosas, que acompanham as secções de jusante de muitos cursos de água, terras de sapais protegidas por restingas instáveis, como em Alvor, em Quarteira e na Ria de Faro-Olhão-Cacela. Nestas destaco as várzeas de Quarteira, tema de fotografias verdadeiramente didácticas, com muitos problemas de drenagem, especialmente antes da fixação pelo homem do leito rectilíneo da secção de jusante da ribeira do mesmo nome: hoje terras de aldeamentos e campos de golfe, antes terras de pequenas hortas familiares de renda, os "Quartos", para cultivos primaveris e estivais, como o milho e a batata doce, regados com picotas e regadores a partir de valas por onde circulavam águas meio salobras, e que foram durante algum tempo também de arrozais, responsáveis pelo sezonismo e suas mortes, tal como noutras várzeas mal drenadas da província, o que o povo reconhecia ao aconselhar que "quem o céu queira, vá primeiro a Aljezur e às várzeas de Quarteira".

No conjunto das fotos, gostaria ainda de ressaltar as que nos proporcionam imagens espectaculares dos caprichos do litoral, dos alcantilados da Costa Vicentina às arribas recortadas nas formações sedimentares do Barlavento e aos estuários sinuosos ao sabor das dinâmicas das restingas arenosas e mais ainda às áreas lagunares; as que evidenciam as áreas de agricultura renovada e intensiva, nomeadamente associada à "plasticultura"; ou as obras portuárias, os molhes de protecção das bacias de atracação interiores, cada vez menos ao serviço da pesca e do comércio e cada vez mais, ao serviço do recreio e do turismo de lazer, num redesenhar das margens; as que exprimem as novas formas de habitar, numa sociedade das mobilidades, do encurtar dos espaços e dos tempos, do apagar dos efeitos das fronteiras, em contextos de explosão primeiro dos voos 
charters e depois das low cost e de aumento considerável dos tempos livres e dos tempos de vida; os novos condomínios mais ou menos vigiados e fechados ao exterior; a renovação do velho casario rural disperso e isolado que fora abandonado pelas populações agrícolas em êxodo; ou a dispersão densa e ordenada de novas habitações unifamiliares, com mais ou menos qualidade, maior ou menor identificação com certas formas da arquitectura regional tradicional, muitas com piscina privada; as que evocam a continuidade dos ritmos sazonais de vida, sazonalidade do passado e do presente.

Nos campos, o trabalho era intenso de Maio a Outubro, com as ceifas, as debulhas, as regas das hortas e a apanha dos frutos secos. Nas praias, a animação, e até mesmo o povoamento, começava com a chegada dos cardumes, e com eles a das companhas das xávegas e armações de sardinha e de atum. O turismo balnear das elites regionais e do Baixo Alentejo, mais ou menos burguesas e fundiárias, apenas reforçava a animação das praias nos meses de Verão, dando lugar às famílias camponesas já no início do Outono, terminadas as colheitas pelo São Miguel. Pontualmente, camponeses algarvios, no sentido do Baixo Algarve, e montanheiros, vinham banhar-se nas águas salgadas do oceano, em busca de um pouco mais de saúde, num excursionismo terapêutico, ou numa migração de algumas semanas outonais em busca de um pouco de iodo e de repouso.

Os novos turismos, que simbolizamos com a construção, nos primeiros anos 60 do passado século, de hotéis de certa dimensão e prestígio, na Praia da Rocha, em Armação de Pêra, em Albufeira e em Monte Gordo, alguns claramente encastrados nas arribas, perpetuaram e reforçaram as velhas sazonalidades da animação das praias, onde o colorido dos barcos e das gentes da pesca, pescadores, armadores e negociantes, foi substituído pelo dos chapéus-de-sol e dos corpos de muitas e desvairadas gentes, de nacionalidades bastante mais diferenciadas do que as que giravam em torno das pescas e das conservas de peixe. Há neste livro excelentes fotografias das praias algarvias, com seus sectores de toldos e de chapéus-de-sol de todas as cores, bem juntinhos, criando por si só certas oportunidades de conhecimento e gerando novos tipos de vizinhança.

Mas os novos turismos também diluem as sazonalidades clássicas, porque são diversificadas as suas motivações e largas as suas margens de liberdade, mesmo se os calendários escolares e empresariais continuam a coarctar as opções e até mesmo as preferências dos casais com filhos jovens em idade escolar e que viajam com eles ou dos activos em certos sectores e empresas: resta todavia o turismo residencial, o turismo de golfe, os turismos cultural ou em busca de ambientes e paisagens amenos e diferentes, e até certos pequenos nichos de procuras mais ou menos exóticas, etc.

A diversificação dos modos de habitar e as dinâmicas das densidades do povoamento, não mais apenas em função do tradicional conceito de população residente, mantém muitos dos ritmos sazonais da vida regional do passado, mas tendem cada vez mais a esbatê-los, justamente quando se apagam os associados à agricultura de sequeiro por abandono quase total da mesma e à pesca tradicional ou de feição já industrial de espécies pelágicas como a sardinha, a cavala e o carapau, também ela concentrada em poucos portos e poucas empresas e deixando à margem muitos dos velhos aglomerados piscatórios, refugiados na pesca artesanal e cada vez mais dependentes do mercado turístico, directa e indirectamente... 